\title{
Authorship Correction: Perspectives of Nonphysician Clinical Students and Medical Lecturers on Tablet-Based Health Care Practice Support for Medical Education in Zambia, Africa: Qualitative Study
}

Sandra Barteit ${ }^{1}$, MA; Florian Neuhann ${ }^{1}$, MD; Till Bärnighausen ${ }^{1,2,3}$, MSc, MD, ScD, PhD; Annel Bowa ${ }^{4}$, MSc; Sigrid Lüders $^{5}$, MD; Gregory Malunga ${ }^{4}$, MSc; Geoffrey Chileshe ${ }^{4}$, BSc; Clemence Marimo ${ }^{6}$, MD; Albrecht Jahn ${ }^{1}$, MSc, $^{2}$ $\mathrm{MD}, \mathrm{PhD}$

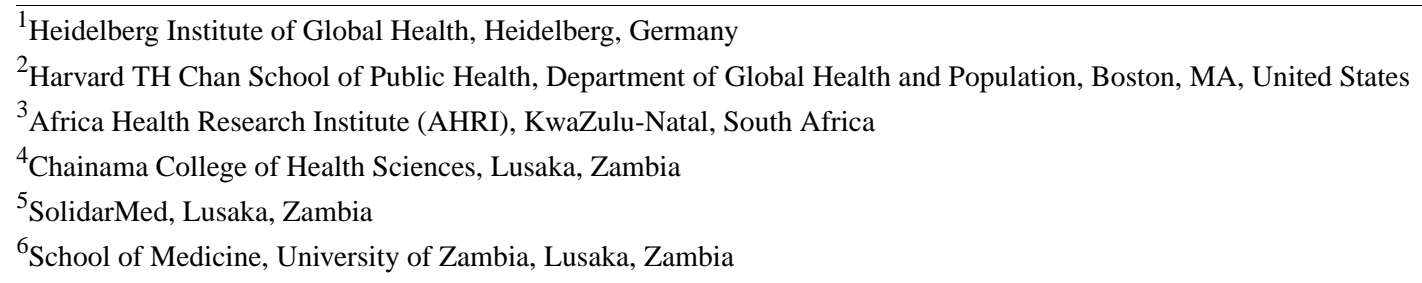

\section{Corresponding Author:}

Sandra Barteit, MA

Heidelberg Institute of Global Health

Im Neuenheimer Feld 130.3

Heidelberg, 69120

Germany

Phone: 4906221 ext 5634030

Email: barteit@uni-heidelberg.de

\section{Related Article:}

Correction of: http://mhealth.jmir.org/2019/1/e12637/

(JMIR Mhealth Uhealth 2019;7(4):e13431) doi: 10.2196/13431

The authors of "Perspectives of Nonphysician Clinical Students and Medical Lecturers on Tablet-Based Health Care Practice Support for Medical Education in Zambia, Africa: Qualitative Study" (JMIR Mhealth Uhealth 2019;7(1):e12637) inadvertently omitted Annel Bowa, MSc (Chainama College of Health Sciences, Lusaka, Zambia) from the list of authors, although initially he had been included as a co-author and had signed the
License to Publish form. He has now been added to the list of authors directly after Till Bärnighausen.

The correction will appear in the online version of the paper on the JMIR website on April 3, 2019, together with the publication of this correction notice. Because this was made after submission to PubMed, PubMed Central, and other full-text repositories, the corrected article also has been resubmitted to those repositories.

\section{Multimedia Appendix 1}

Letter from authors requesting correction.

[PDF File (Adobe PDF File), 465KB-Multimedia Appendix 1] 
Edited by G Eysenbach; this is a non-peer-reviewed article. Submitted 17.01.19; accepted 18.01.19; published 03.04.19.

Please cite as:

Barteit S, Neuhann F, Bärnighausen T, Bowa A, Lüders S, Malunga G, Chileshe G, Marimo C, Jahn A

Authorship Correction: Perspectives of Nonphysician Clinical Students and Medical Lecturers on Tablet-Based Health Care Practice

Support for Medical Education in Zambia, Africa: Qualitative Study

JMIR Mhealth Uhealth 2019;7(4):e13431

URL: https://mhealth.jmir.org/2019/4/e13431/

doi: 10.2196/13431

PMID: 30943169

CSandra Barteit, Florian Neuhann, Till Bärnighausen, Annel Bowa, Sigrid Lüders, Gregory Malunga, Geoffrey Chileshe, Clemence Marimo, Albrecht Jahn. Originally published in JMIR Mhealth and Uhealth (http://mhealth.jmir.org), 03.04.2019. This is an open-access article distributed under the terms of the Creative Commons Attribution License (https://creativecommons.org/licenses/by/4.0/), which permits unrestricted use, distribution, and reproduction in any medium, provided the original work, first published in JMIR mhealth and uhealth, is properly cited. The complete bibliographic information, a link to the original publication on http://mhealth.jmir.org/, as well as this copyright and license information must be included. 